\title{
Sequential Treatment Reduces the Acute Phases of Adverse Effect of Zoledronic Acid in First Time Users
}

\author{
Jinmei Deng ${ }^{1 *}$, Dongmei Cai ${ }^{*}$, Suming Jie ${ }^{1}$, Enjing Chen${ }^{1}$, Xiuzhen Cai ${ }^{1}$, Yanbing Li ${ }^{2 \#}$ \\ ${ }^{1}$ Outpatient Clinic of Internal Medicine Department, The First Affiliated Hospital, Sun Yat-sen University, Guangzhou, China \\ ${ }^{2}$ Department of Endocrinology, The First Affiliated Hospital, Sun Yat-sen University, Guangzhou, China \\ Email: "easd04lyb@126.com,309346496@qq.com,13500037898@163.com, jiesuming@126.com, 745349206@qq.com, \\ caixiuzhen66@126.com
}

How to cite this paper: Deng, J.M., Cai, D.M., Jie, S.M., Chen, E.J., Cai, X.Z. and Li, Y.B. (2018) Sequential Treatment Reduces the Acute Phases of Adverse Effect of Zoledronic Acid in First Time Users. Open Journal of Preventive Medicine, 8, 189-205. https://doi.org/10.4236/ojpm.2018.87018

Received: June 20, 2018

Accepted: July 15, 2018

Published: July 18, 2018

Copyright $\odot 2018$ by authors and Scientific Research Publishing Inc. This work is licensed under the Creative Commons Attribution International License (CC BY 4.0).

http://creativecommons.org/licenses/by/4.0/

(c) (i) Open Access

\begin{abstract}
Objective: To investigate whether sequential regimen such as traditional anti-reabsorption medications followed by zoledronic acid could reduce the side effects after initiation of zoledronic acid in postmenopausal osteoporosis patients. Methods: A total of 156 postmenopausal osteoporosis patients who presented at our osteoporosis outpatient clinic were enrolled in this study. They were randomly divided into four groups: the control group, alendronate group, calcitonin group, and raloxifene group. All participants were treated with Caltrate $600 \mathrm{mg}$ per day and calcitriol $0.25 \mathrm{ug}$ per day as a baseline treatment, followed by administrating $5 \mathrm{mg} / 100 \mathrm{~mL}$ of zoledronic acid intravenously for one single time three months afterwards. During the abovementioned course of three months, the alendronate group received $70 \mathrm{mg}$ of alendronate sodium orally once a week, the calcitonin group received nasal spray form of salmon calcitonin 10iu daily, the raloxifene group received $60 \mathrm{mg}$ of raloxifene orally daily, and the control group received nothing but only the baseline treatment. We tested parameters such as $\beta$-cross, blood calcium level, renal function both pre and post zoledronic acid treatment. We also documented those side effects that typically occurred within one week of treatment initiation, which included the proportion, severity, onset time, and duration of the fever, demand for pain medication, severity of bone and joint pain, flu-like symptoms, arrhythmia, blood calcium level, and kidney function impairment. We also evaluated how willing the patients were to receive a second dose of zoledronic acid. Then we did comparative analysis between control group and sequential group. Results: The side effects such as fever, bone and joint pain, flu-like symptoms after zoledronic acid treatment in alendronate
\end{abstract}

${ }^{*}$ Authors contributed equally. 
group and calcitonin group were all significantly lower than that in control group, while raloxifene group showed no significant difference compared to that in the control group. The proportions of patients who needed NSAIDs in the alendronate group and the calcitonin group were significantly lower than that in control group. However, the raloxifene group showed no significant difference in the NSAIDs demand from that of the control group. The percentages of patients who consented to a second dose of zoledronate therapy in the alendronate, calcitonin and raloxifene groups were significantly higher than that in the control group. Conclusions: Sequential treatment with alendronate sodium or calcitonin can significantly reduce the side effects such as fever, bone/joint pain, flu-like symptoms caused by first-time zoledronic acid therapy. Raloxifene sequential treatment does not seem to have decreased or increased the side effects of zoledronic acid treatment. Also, sequential treatment can improve the patient compliance with a second dose of zoledronic acid.

\section{Keywords}

Zoledronic Acid, Alendronate Sodium, Raloxifene, Calcitonin,

Postmenopausal, Osteoporosis, Adverse Reaction

\section{Introduction}

Presently, anti-reabsorption medications are most widely used for treating osteoporosis. Zoledronic acid (Aclasta) is a common clinical anti-reabsorption medication. As a third generation of bisphosphonates (BPs), it outperforms the previous nitrogen-containing BPs in improving patients' balance and quality of life by inhibiting bone reabsorption and increasing bone mineral density (BMD) [1] [2]. It is administrated via intravenous drip infusion once a year, which, therefore, brings good compliance with treatment. However, those who have been treated with zoledronic acid intravenously are likely to suffer from acute side effects, such as fever, bone and joint pain and flu-like symptoms, especially after the first administration [3]. Although the common adverse reactions generally disappear within $72 \mathrm{~h}$, or in rare cases, last 7 to 10 days without recurrence, they have serious impacts on the aging population, especially those with underlying diseases. Thus, the patients who are afraid of any adverse reactions or have suffered from any side effects during the first administration may show poor compliance with the second dose and refuse the clinical application of zoledronic acid. It can be observed from relevant clinical reports that the acute-phase response is less prevalent among the patients who have received other anti-reabsorption medications, and no significant adverse event occurs after the first administration of zoledronic acid. This study aims to investigate whether sequential regimen, namely, traditional anti-reabsorption medications (alendronate sodium, calcitonin or raloxifene) followed by zoledronic acid could reduce or mitigate the acute side effects brought by zoledronic acid administra- 
tion in postmenopausal patients with osteoporosis.

\section{Materials and Methods}

\subsection{Subjects}

The clinical data of 156 postmenopausal patients with osteoporosis who presented at our osteoporosis outpatient clinic between January 1, 2015 and June 2017 were analyzed in this study. These patients were postmenopausal women aged 50 to 80 (mean age $=68.5 \pm 8.3$ ). Prior to the initial diagnosis, dual-energy X-ray absorptiometry (DXA) was used to test each patient's bone density (lumbar vertebra and femur) and the measured values were considered to be diagnosis and inclusion criteria. Patients were eligible for inclusion if bone mineral density $\mathrm{T}$-score was no greater than -2.5 or $\mathrm{T}$-score was less than -1.0 with preexisting fragility fractures and definite systemic symptoms such as back pain or height loss. Other inclusion criteria include: 1) normal blood calcium; 2) creatinine clearance rate $(\mathrm{CCR})>35 \mathrm{ml} / \mathrm{min}$. Meanwhile, it should be the first time for each patient to receive zoledronic acid with informed consent. Exclusion criteria: 1) previous use (within six months before treatment) of estrogen, glucocorticoid (GC), calcitonin and other BPs that might influence one's bone metabolism; 2) diabetes and endocrine disorders of thyroid, parathyroid, adrenal gland or gonad; 3) CCR $\leq 35 \mathrm{ml} / \mathrm{min}$; 4) secondary osteoporosis; 5) an allergy to zoledronic acid, alendronate sodium, calcitonin or raloxifene.

\subsection{Methods}

This was an open, randomized, placebo-controlled, prospective study involving postmenopausal women with osteoporosis who were divided into a control group, an alendronate sodium zoledronic acid sequential group (alendronate group), a calcitonin zoledronic acid sequential group (calcitonin group) and a raloxifene zoledronic acid sequential group (raloxifene group). Each patient was administrated Caltrate $(600 \mathrm{mg} / \mathrm{d})$ and calcitriol $(0.25 \mathrm{ug} / \mathrm{d})$ at baseline and then assigned to receive zoledronic acid (5 $\mathrm{mg}$ as an IV infusion) after three months. The patients used Caltrate and calcitriol at baseline during the first three months formed the control group; during this course of treatment, other patients were respectively assigned to receive baseline concomitant medications including 70 $\mathrm{mg}$ alendronate sodium orally once a week (alendronate group), nasal spray form of salmon calcitonin 100iu per day (calcitonin group), and $60 \mathrm{mg}$ raloxifene orally per day (raloxifene group).

The abovementioned medications were administrated in strict accordance with relevant instructions. The patients were recommended to drink plenty of water during the day of infusion and received hydration $(0.9 \%$ NS $250 \mathrm{ml})$ prior to zoledronic acid administration via intravenous drip infusion $(5 \mathrm{mg} / 100 \mathrm{ml})$ over $15 \mathrm{~min}$ and rehydration (0.9\% NS $250 \mathrm{ml})$.

Zoledronic acid (Aclasta) is Novartis' once-yearly injection that provides fracture protection in postmenopausal osteoporosis. Alendronate sodium (Fo- 
samax) is a once-weekly medicine developed and manufactured by Merck \& Co for the treatment of osteoporosis. Calcitonin-salmon (Miacalcin) nasal spray is a Novartis product for postmenopausal osteoporosis treatment. Raloxifene (Evista) is produced by Eli Lilly and Company. Caltrate is supplied by Pfizer Consumer Healthcare in China. Calcitriol (Rocaltrol) is purchased from Shanghai Roche Pharmaceuticals Ltd. Bufferin Plus produced by Sino-American Shanghai Squibb Pharmaceuticals Co., Ltd. was used in the NSAIDs trial.

\subsection{Outcome Measures}

Relevant parameters including pain score, adverse reaction, blood calcium, renal function and $\beta$-cross of each patient were monitored prior to zoledronic acid administration in the third month; the adverse reactions caused by zoledronic acid, such as fever, bone and joint pain, flu-like symptoms, arrhythmia, use of NSAIDs, post-treatment blood calcium level and renal impairment, were documented a week after the administration. A follow-up visit questionnaire was distributed to each participant and collected on the spot. The monitoring indicators are as follows:

1) Fever: Before intravenous infusion, each patient was required to take her axillary temperature with a mercurial thermometer for $10 \mathrm{~min}$ to identify whether she had a fever or not. A patient who had a fever prior to zoledronic acid administration was ineligible for the study. When a patient had received zoledronic acid via intravenous drip infusion for $15 \mathrm{~min}$, her axillary temperature should be taken again with the same mercurial thermometer. An axillary temperature higher than $37.4^{\circ} \mathrm{C}$ was considered to be a fever. For those with normal body temperatures, their axillary temperatures should be taken hourly within four hours. If a patient felt like having a fever, she should monitor her own axillary temperature; otherwise, the patient was required to respectively take her axillary temperature at 10:00 of the day following the administration and then at 15:00 on the day after that. In the following five days, those with normal body temperatures during the previous two days were required to take their axillary temperatures at 10:00 every day. Anyone having a fever during the week after zoledronic acid administration sought medical attention from the researchers as required. When one's body temperature exceeded $38.5^{\circ} \mathrm{C}$, NSAIDs could be applied if appropriate.

2) Bone and joint pain: This category of monitoring indicators includes back pain and knee joint pain.

3) Flu-like symptoms: After zoledronic acid administration, some might suffer from fever (body temperature above $37.5^{\circ} \mathrm{C}$ ) accompanied with chills, exhaustion, headache, dizziness, body aches and catarrh, or odynophagia, snuffling, rhinorrhea, nausea, vomiting, depraved appetite, diarrhea and abdominal pain.

4) Arrhythmia: In case of palpitation and chest distress, one should promptly receive ECG at the hospital.

5) The blood calcium level, renal function and $\beta$-cross of each patient were measured upon enrollment and three months later. Then, the renal function and blood calcium level were tested again a week after zoledronic acid treatment. 
6) The follow-up visit questionnaire was distributed to investigate how many patients agreed to receive a second dose of zoledronic acid.

When a patient's body temperature reached $37.4^{\circ} \mathrm{C}$ and above, she was deemed to have a fever, which was further classified as low fever $\left(37.4^{\circ} \mathrm{C}\right.$ $\left.38.0^{\circ} \mathrm{C}\right)$, moderate fever $\left(38.1^{\circ} \mathrm{C}-39.0^{\circ} \mathrm{C}\right)$, ardent fever $\left(39.1^{\circ} \mathrm{C}-41.0^{\circ} \mathrm{C}\right)$ and hyperpyrexia (above $41.0^{\circ} \mathrm{C}$ ).

Myosalgia, arthralgia and headache: The Visual Analogue Scale (VAS) was used for pain assessment. VAS (4-point scale): 1-No pain; 2-Mild pain (without affecting sleep); 3-Moderate pain (affecting sleep at a tolerable degree); 4-Severe pain (intolerable, unable to fall asleep).

\subsection{Statistical Analysis}

The statistical analysis software SPSS 22.0 was employed to analyze the patients' general information and body temperatures in this study. To be specific, the $\mathrm{t}$-test was applied to the intergroup comparison of measurement data while that of enumeration data was performed by means of the chi-square test to illustrate the difference between the three sequential groups and the control group in the prevalence of adverse reactions. $P<0.05$ indicated a difference of statistical significance.

\section{Results}

\subsection{General Information}

All patients made full participation in the study without withdrawal and no significant adverse reaction was observed during the first three months of treatment at baseline. As shown in Table 1, there is basically no marked adverse reaction within the abovementioned course of treatment. According to the

Table 1. Patients' general information by group.

\begin{tabular}{|c|c|c|c|c|c|c|}
\hline & Control Group & Alendronate Group & Calcitonin Group & Raloxifene Group & & \\
\hline Number of cases & 39 & 39 & 39 & 39 & & \\
\hline Age (yr) & $70.5 \pm 8.4$ & $67.8 \pm 9.3$ & $67.4 \pm 8.1$ & $68.4 \pm 7.4$ & 1.087 & 0.356 \\
\hline BMI & $22.25 \pm 0.123$ & $22.07 \pm 3.06$ & $21.88 \pm 2.88$ & $2.39 \pm 2.66$ & 0.231 & 0.875 \\
\hline $\mathrm{L}_{2-4} \mathrm{BMD}$ & $0.792 \pm 0.123$ & $0.793 \pm 0.12$ & $0.783 \pm 0.102$ & $0.797 \pm 0.110$ & 0.101 & 0.859 \\
\hline Femoral neck BMD & $0.606 \pm 0.087$ & $0.613 \pm 0.108$ & $0.583 \pm 0.195$ & $0.604 \pm 0.088$ & 0.396 & 0.756 \\
\hline Pre-treatment VAS & $1.51 \pm 0.601$ & $1.54 \pm 0.682$ & $1.46 \pm 0.682$ & $1.36 \pm 0.584$ & 0.601 & 0.615 \\
\hline Pre-treatment CCR & $56.232 \pm 16.10$ & $58.64 \pm 14.00$ & $60.81 \pm 14.77$ & $61.07 \pm 12.04$ & 1.119 & 0.343 \\
\hline Pre-treatment $\mathrm{Ca}$ & $2.30 \pm 0.07$ & $2.31 \pm 0.11$ & $2.32 \pm 0.10$ & $2.29 \pm 0.09$ & 1.38 & 1.25 \\
\hline$\beta$-cross & $0.427 \pm 0.166$ & $0.424 \pm 0.162$ & $0.415 \pm 0.122$ & $0.419 \pm 0.121$ & 0.025 & 0.995 \\
\hline
\end{tabular}

Note: Age unit: year (yr); BMI unit: kg/m²; Ca unit: $\mathrm{mmol} / \mathrm{L} ; \mathrm{CCR}=[(140-$ age $) \times$ weight $(\mathrm{kg})] /[0.818 \times \mathrm{Scr}(\mathrm{umol} / \mathrm{L})] \times 0.85 ; \mathrm{BMD}$ unit: $\mathrm{mg} / \mathrm{cm}{ }^{2}$. 
one-way ANOVA concerning each group's age, BMI, BMD, pre-treatment pain score, pre-treatment CCR, blood calcium (Ca) level and $\beta$-cross, all intergroup $P$ values are greater than 0.05 , that is, the intergroup differences show no statistical significance but comparability.

\subsection{Adverse Reactions a Week after Intravenous Drip Infusion of Zoledronic Acid}

According to the data about fever in Table 2, there are fewer cases of fever in the alendronate group and calcitonin group than the control group. For the comparison between the alendronate group and the control group, $x^{2}=10.40$ and $P=$ 0.001; as to the comparison between the calcitonin group and the control group, $x^{2}$ $=6.724$ and $P=0.010$, there are statistically significant differences between the control group and the two sequential groups. On the other hand, the difference between the raloxifene group and the control group shows no statistical significance $\left(x^{2}=3.021, p=0.082\right)$. In terms of fever peak value, when comparing the control group with the sequential groups, the $P$-values are respectively 0.002 (control group vs. alendronate group), 0.004 (control group vs. calcitonin group) and 0.06 (control group vs. raloxifene group). In other words, each of the alendronate and calcitonin groups has a lower fever peak value than the control group. The difference between the control group and each sequential group in onset and duration of fever is not statistically significant. As to bone and joint pain VAS1-3 (pre and post-treatment), the $P$-values are respectively 0.001 (control group vs. alendronate group), 0.002 (control group vs. calcitonin group) and 0.15 (control group vs. raloxifene group), which suggests that alendronate sodium and calcitonin can ease the acute-phase pain in the zoledronic acid-treated subjects. With regard to flu-like symptoms, the $P$-values are respectively 0.01 (control group vs. alendronate group), 0.03 (control group vs. calcitonin group) and 0.055 (control group vs. raloxifene group). Compared to the control group, the flu-like symptoms are substantially reduced in the alendronate and calcitonin groups, and the difference is of statistical significance. Basically, no increased

Table 2. Acute-phase adverse reactions a week after zoledronic acid treatment.

\begin{tabular}{|c|c|c|c|c|c|c|c|c|c|}
\hline & $\begin{array}{c}\text { Number of } \\
\text { Cases }\end{array}$ & $\begin{array}{c}\text { Fever } \\
(\text { Case }(\mathrm{s}) / \%)\end{array}$ & $\begin{array}{c}\text { Average Fever } \\
\text { Peak Value }\left({ }^{\circ} \mathrm{C}\right)\end{array}$ & $\begin{array}{c}\text { Onset of Fever } \\
\text { (h) }\end{array}$ & $\begin{array}{c}\text { Duration of } \\
\text { Fever (h) }\end{array}$ & $\begin{array}{l}\text { Bone and Joint } \\
\text { Pain (VAS1-3) }\end{array}$ & $\begin{array}{c}\text { Flu-like } \\
\text { Symptoms } \\
\text { (Case }(\mathrm{s}) / \%)\end{array}$ & $\begin{array}{c}\text { Renal } \\
\text { Function } \\
\text { Impairment }\end{array}$ & Arrhythmia \\
\hline Control group & 39 & $15 / 38.5$ & $38.5 \pm 0.4$ & $19.3 \pm 12.9$ & $21.7 \pm 11.1$ & $-0.308 \pm 0.766$ & $12 / 30.8$ & $0 / 0$ & $0 / 0$ \\
\hline $\begin{array}{l}\text { Alendronate } \\
\text { group }\end{array}$ & 39 & $3 / 7.7^{*}$ & $37.9 \pm 0.2^{\star}$ & $20.0 \pm 8.7^{\times}$ & $15.8 \pm 8.2^{\times}$ & $0.282 \pm 0.514^{\star}$ & $2 / 5.1^{*}$ & $0 / 0$ & $0 / 0$ \\
\hline $\begin{array}{l}\text { Calcitonin } \\
\text { group }\end{array}$ & 39 & $5 / 12.8^{*}$ & $38.0 \pm 0.2^{*}$ & $16.6 \pm 7.3^{\times}$ & $17.0 \pm 9.8^{\times}$ & $0.256 \pm 0.549^{\star}$ & $3 / 7.7^{\star}$ & $0 / 0$ & $0 / 0$ \\
\hline $\begin{array}{l}\text { Raloxifene } \\
\text { group }\end{array}$ & 39 & $8 / 20.5^{\times}$ & $38.0 \pm 0.9^{\times}$ & $18.0 \pm 6.7^{\times}$ & $20.7 \pm 8.7^{\times}$ & $0.103 \pm 0.447^{\times}$ & $5 / 12.8^{\times}$ & $0 / 0$ & $0 / 0$ \\
\hline
\end{tabular}

Note: VAS1-3 denotes the decrease in the pain scores of the patients after zoledronic acid treatment compared to that upon enrollment; ${ }^{\star}$ indicates a statistically significant difference between the corresponding sequential group and the control group $(P<0.05)$; $\times$ suggests that the difference between a given sequential group and the control group shows no statistical difference $(P>0.05)$. 
creatinine or arrhythmia was reported during the treatment course. To summarize, pretreatment with alendronate sodium and calcitonin can reduce the occurrence of fever, bone and joint pain and flu-like symptoms following the first zoledronic acid infusion; however, raloxifene has no such effects.

\subsection{Intergroup Comparison of Ca, CCR and $\beta$-Cross a Week after Treatment}

As shown in Table 3, the decline in $\beta$-cross of each sequential group after treatment is statistically significant compared to that of the control group. This indicates that alendronate, calcitonin and raloxifene can inhibit bone reabsorption by reducing $\beta$-cross to a given level. Through analysis, no statistically significant difference is observed between the sequential groups and the control group in the pre and post-treatment CCRs and Ca. The $P$-value concerning the difference between the pre and post-treatment $\mathrm{Ca}$ and CCRs of each sequential group and that of the control group is greater than 0.05 , that is, the renal function and $\mathrm{Ca}$ of each group are not affected by the medications.

\subsection{NSAIDs Use}

Table 4 shows the NSAIDs use reduced by alendronate and calcitonin after the initial zoledronic acid administration.

\subsection{Intergroup Comparison of Willingness to Receive a Second Dose of Zoledronic Acid}

Table 5 reveals the number and proportion of the patients in each group who agreed to receive a second dose of zoledronic acid. By comparison, there is a statistically significant difference between each sequential group and the control group in this respect, which suggests a marked increase in compliance after the corresponding sequential treatment. Among those who refused a second infusion, a large number of these patients were worried about the zoledronic

Table 3. Differences between pre and post-treatment $\beta$-cross, Ca and CCRs by group.

\begin{tabular}{|c|c|c|c|c|c|c|c|}
\hline & Number of cases & $\beta$ - rross $_{1-2}$ & $\mathrm{Ca}_{1-3}$ & $\mathrm{CCR}_{1-3}$ & $P_{1}$ & $P_{2}$ & $P_{3}$ \\
\hline Control group & 39 & $-0.008 \pm 0.052$ & $0.027 \pm 0.064$ & $0.412 \pm 3.642$ & - & - & - \\
\hline Alendronate group & 39 & $0.144 \pm 0.119$ & $0.029 \pm 0.090$ & $1.614 \pm 2.948$ & 0.001 & 0.506 & 0.113 \\
\hline Calcitonin group & 39 & $0.123 \pm 0.0750$ & $0.038 \pm 0.062$ & $0.653 \pm 4.918$ & 0.001 & 0.32 & 0.807 \\
\hline Raloxifene group & 39 & $0.124 \pm 0.079$ & $0.037 \pm 0.090$ & $0.478 \pm 9.287$ & 0.001 & 0.243 & 0.967 \\
\hline
\end{tabular}

Note: $\beta$ - cross $_{1-2}$ means the difference between the $\beta$-cross values upon enrollment and after zoledronic acid treatment; Ca $a_{1-3}$ refers to the decrease in the Ca level of each group upon enrollment and a week after zoledronic acid administration; $\mathrm{CCR}_{1-3}$ represents the difference between the CCRs upon enrollment and a week after the treatment. $P_{1}, P_{2}$ and $P_{3}$ respectively express the $P$-values based on the comparison of the abovementioned indicators $\left(\beta\right.$-cross ${ }_{1-2}$, Ca $\mathrm{a}_{1-3}$ and $\mathrm{CCR}_{1-3}$ ) between each sequential group and the control group. 
Table 4. Comparison of NSIADs use by group.

\begin{tabular}{|c|c|c|c|}
\hline \multirow{2}{*}{ Group } & \multicolumn{2}{|c|}{ NSAIDs Use } & \multirow[t]{2}{*}{ Proportion } \\
\hline & No & Yes & \\
\hline Control group & 27 & 12 & $30.8 \%$ \\
\hline Alendronate group & 36 & 3 & $7.7 \%$ \\
\hline Calcitonin group & 37 & 2 & $5.1 \%$ \\
\hline Raloxifene group & 32 & 6 & $14.0 \%$ \\
\hline Total & 132 & 24 & $15.4 \%$ \\
\hline
\end{tabular}

Note: The chi-squared test results are as follows: control group vs. alendronate group: $x^{2}=6.686, P=0.01$; control group vs. calcitonin group: $x^{2}=8.705, P=0.03$; control group vs. raloxifene group: $x^{2}=0.375, P=$ 0.066 .

Table 5. Intergroup comparison of willingness to receive a second dose of zoledronic acid.

\begin{tabular}{cccccc}
\hline & Agree & \multicolumn{5}{c}{ Disagree (Cases \& Reasons) } \\
\cline { 3 - 6 }$($ Cases/\%) & $\begin{array}{c}\text { Adverse } \\
\text { Reaction }\end{array}$ & $\begin{array}{c}\text { Medical } \\
\text { Expense }\end{array}$ & $\begin{array}{c}\text { Preference for } \\
\text { Medicines in Use }\end{array}$ & $\begin{array}{c}\text { Lack of } \\
\text { Self-awareness }\end{array}$ \\
\hline $\begin{array}{c}\text { Control group } \\
\text { Alendronate } \\
\text { group }\end{array}$ & $25 / 64.1 \%$ & 12 & 1 & 0 & 1 \\
$\begin{array}{c}\text { Calcitonin } \\
\text { group }\end{array}$ & $37 / 94.5 \%^{*}$ & 1 & 1 & 0 & 0 \\
$\begin{array}{c}\text { Raloxifene } \\
\text { group }\end{array}$ & $34 / 87.2 \%^{*}$ & 2 & 1 & 2 & 0 \\
\hline
\end{tabular}

Note: The chi-squared test results are as follows: control group vs. alendronate group: $x^{2}=11.323, P=0.03$; control group vs. calcitonin group: $X^{2}=5.636, P=0.018$; control group vs. raloxifene group: $X^{2}=5.636, P=$ 0.018 . The difference between each sequential group and the control group shows statistical significance.

acid-associated adverse reactions while others might make such a decision because they could not afford the medical costs or lacked a sufficient awareness of relevant diseases. Hence, to increase patient compliance with zoledronic acid treatment, the possible adverse reactions, as well as the patient's financial situation, should be taken into account.

\section{Discussion}

As zoledronic acid becomes an extensively used clinical medication, an increasing number of reports on relevant adverse reactions caused by zoledronic acid, especially the acute-phase one, are presented to the public. Reid, et al. carried out a multicenter international trial involving 7765 postmenopausal women with osteoporosis to explore the characteristics of the acute-phase response (APR) after zoledronic acid, and found that $42.7 \%$ of the zoledronic acid group had a fever or flu-like symptoms after the first infusion, compared with $11.7 \%$ of the placebo group. Despite the fact that most APR components were rated as mild or moderate, severe adverse events occurred in 30 zoledronic acid-treated subjects 
[4]. According to the previous studies on the adverse reactions brought by zoledronic acid, it is widely accepted that the IV dose of zoledronic acid is that, on one hand, 25 - 114 times more efficient than alendronate sodium in osteoclast proliferation inhibition and apoptosis acceleration by suppressing the biosynthesis initiated by farnesyl pyrophosphate (FPP) [5]; on the other hand, zoledronic acid acts on peripheral blood monouclear cells (PBMCs) to realize rapid accumulation of the upstream geranylgeranyl pyrophosphate (GGPP) and dimethylallyl pyrophosphate (DMAPP) while it is bound with T-cell receptors to activate $\mathrm{T}$ cells, thereby promoting the proliferation of $\mathrm{T}$ cells and the release of tumor necrosis factor (TNF) $\alpha$ and interleukin-6 (IL-6) that ultimately lead to an inflammation. Clinically, the common adverse reactions associated with zoledronic acid include fever, flu-like symptoms and myalgia. These adverse reactions disappear as the inflammatory substances are cleared within a short time [6] [7]. Also, it is reported that the peaks in plasma IL-6 were correlated with the peaks in temperature and in serum CRP values [8]. Based on the abovementioned studies and the clinical findings, the occurrence of acute-phase adverse reactions has been significantly reduced in the patients with a history of non-zoledronic acid anti-reabsorption medications after zoledronic acid treatment or a second infusion. This study attempts to develop an appropriate sequential regimen that reduces the adverse reactions caused by the first dose of zoledronic acid.

Fever and flu-like symptoms: after sequential treatment, there were fewer cases of zoledronic acid-related fever and flu-like symptoms in the alendronate and calcitonin groups and lower peaks in temperature. As to the onset and duration of fever, it basically occurred within two days after infusion and disappeared three days later. There is no statistically significant difference between each sequential group and the control group. Adami, S., et al. indicated that the acute-phase response (APR) caused by zoledronic acid administration was associated with the lowest dose; besides, the APR would be provoked by a given dose only, which, at the same time, would render cells insensitive to further stimulation for several months [9]. As anti-reabsorption medications, zoledronic acid outperforms alendronate sodium and calcitonin in inhibiting bone reabsorption [10]. Therefore, the alendronate sodium or calcitonin administration three months before zoledronic acid also contributed to the inhibited bone reabsorption and slowed down bone metabolism by suppressing osteoclast proliferation; on the other hand, alendronate sodium and calcitonin could desensitize inflammatory cells without bringing forth a fever or flu-like symptoms, in which way they ultimately reduced relevant APRs and lowered the peaks of temperature following the first zoledronic acid administration. $\beta$-cross was a bone reabsorption inhibition marker in this study. Through statistical analysis, there is a decline in the $\beta$-cross after sequential treatment with different medications. The difference between each sequential group and the control shows statistical significance. However, no statistically significant difference is observed between the 
raloxifene group and the control group in fever and flu-like symptoms. This is probably associated with the mechanism of action of raloxifene and the abovementioned APR. As a second-generation selective estrogen receptor modulator (SERM), raloxifene has estrogenic action on bones by binding with the estrogen receptor. The gene expression of transforming growth factor- $\beta$ (TGF- $\beta$ ) is up-regulated to inhibit the proliferation and differentiation of the precursor cells of osteoclasts and suppress osteoclast formation; besides, raloxifene may directly deactivate mature osteoclasts with hyperoxides, thereby inhibiting bone reabsorption and increasing bone density [11]. Also, such APRs as flushes and flu-like symptoms may occur after raloxifene. According to a meta-analysis of the therapeutic efficacy of raloxifene on postmenopausal osteoporosis, a total of 11 randomized controlled trials suggested that raloxifene-related APRs included flushes and flu-like symptoms [12]. In this study, the raloxifene group did not complain of obvious flushes and flu-like symptoms during the three-month treatment probably because raloxifene is not an effective inhibitor of bone reabsorption. By intergroup comparison of the $\beta$-cross values before and after the corresponding treatment, raloxifene is not as efficient as the other two medications in inhibiting bone reabsorption. Therefore, there is no significant difference in APR between the sequential group and the control group. Although the difference between the raloxifene group and the control group in the data about fever and flu-like symptoms is not statistically significant, the study results reveal a notable decline in the cases of fever and flu-like symptoms in the raloxifene group. Therefore, the insignificant difference between the two groups might be associated with the number of patients and further study in a greater scale. And it is required to determine the therapeutic efficacy of raloxifene through clinical observation.

Osteoporosis has been called the "silent killer" because early stages of the disease are difficult to detect and diagnose. In this study, the severity of bone pains was largely rated as no pain and mild; in most cases, the patients only reported significant bone pains when fractures occurred. Primary osteoporosis is a long-term, chronic condition. The pathogenesis of bone pains mainly includes 1) destruction of bone microstructure and secondary muscle spasm caused by excessive bone transformation, primarily bone reabsorption, and 2) fractures, especially fragility and compression fractures of vertebral body and fracture of hip. With regard to the acute-phase bone and joint pain in some patients after zoledronic acid administration, it is mainly contributed by inflammatory factors and thus can be gradually mitigated by clearing the inflammatory factors. From the study results, alendronate sodium and calcitonin can reduce the occurrence of acute-phase pains following zoledronic acid treatment. Alendronate sodium is considered a second-generation bisphosphonate that adheres to the bone surface and eases bone pains by inhibiting bone reabsorption and osteoclasia. Calcitonin-salmon is a synthetic polypeptide of 32 amino acids in the same linear sequence that is found in calcitonin of salmon origin. It can combine with the cal- 
citonin receptor in osteoclasts, which not only inhibits the development and activity of osteoclasts, but also encourages osteoclasts to produce a massive number of cyclic adenosine monophosphates (CAMPs) to activate protein kinases (PKs), thereby suppressing bone reabsorption and alleviating the bone and joint pain [13] [14]. It is also reported that calcitonin acts on the nerve center to increase the $\beta 2$-EP concentration and relieve pain by combining $\beta 2$-EP and the opioid receptor. Apart from this, it has been clinically proved that calcitonin acts on the hypothalamus with specific receptors to regulate the sense of pain in the central nervous system [10]. Therefore, calcitonin is an appropriate medication for osteoporosis with a clinically significant pain. However, the possible APR (e.g., flushes, nausea) reduces the compliance with daily use of calcitonin. In this case, a sequential regimen can be adopted by replacing calcitonin with zoledronic acid.

In terms of NSAIDs use, there was a sharp decline in the alendronate and calcitonin groups, which is associated with the decreased adverse reactions such as fever, flu-like symptoms and bone and joint pain. Further, alendronate sodium is able to lower the peaks of temperature while calcitonin plays a significant role in relieving bone pains.

Zoledronic acid may reduce the blood calcium level and lead to such symptoms of acalcerosis as a tic of limbs. In fact, since each patient had a normal blood calcium level upon enrollment and received Caltrate and calcitriol before zoledronic acid, no hypocalcemia occurred within the course of treatment. On this basis, $\mathrm{Ca}$ and Vitamin D supplementation plays an important part in maintaining blood calcium in the normal range and preventing hypocalcemia after zoledronic acid treatment even though a meta-analysis indicates that $\mathrm{Ca}$ and $\mathrm{Vi}$ tamin D supplementation cannot reduce the risk of osteoporosis and fractures [15].

The correlation between zoledronic acid and arrhythmia, especially atrial fibrillation, remains controversial. In UK, the zoledronic acid-treated patients are informed that the medication may elevate the risk of atrial fibrillation because of a clinical trial where it is found that female patients having received IV infusion of zoledronic acid are exposed to a higher risk of the disease [16]. Kim, D.H., et al. performed a meta-analysis to investigate the correlation between bisphosphonates and cardiovascular (CV) events and drew a conclusion that bisphosphonates did not have beneficial or harmful effects on atherosclerotic CV events, but zoledronic acid might modestly increase the risk of atrial fibrillation [17]. According to another meta-analysis, there is no association between bisphosphonate exposure and atrial fibrillation [18]. In this study, no patient had atrial fibrillation. This implies that atrial fibrillation is indeed a rare case, and the sequential regimen does not necessarily mean an elevated risk of arrhythmia. Nevertheless, the absence of atrial fibrillation is probably related to the inclusion criteria that consider those with heart diseases, especially arrhythmia, ineligible candidates for the study and the Ca supplement provided for the patients to en- 
sure their blood calcium levels.

The renal impairment associated with zoledronic acid is another cause for concern. In US, it is reported that the zoledronic acid-treated patients may suffer from relevant renal injury and even renal failure. The cases with acute deterioration of renal function associated with zoledronic acid treatment between 2001 and 2004 were drawn by French scholars from the French Adverse Event Reporting System database. A total of 71 adverse events were identified, including seven patients who had experienced renal impairment after various durations of zoledronic acid therapy ( 1 - 120 days). Among these adverse events, three were acute deterioration of preexisting chronic renal failure, another three experienced complete recovery and one reported partial recovery of previous renal function. The chronic renal impairment led to a fatal outcome in two cases. The study indicated that the risk factors for zoledronic acid-associated renal impairment included multiple myeloma, preexisting renal insufficiency, concomitant use of nephrotoxic drugs, insufficient hydration during treatment and a short IV infusion time ( $<15 \mathrm{~min})$. According to the study, although renal impairment is not commonly seen in the zoledronic acid-treated patients, the therapy has severe adverse effects. In fact, these adverse reactions are quite rare [19]. To prove this point, the participants with CCR $<35 \mathrm{ml} / \mathrm{min}$ and serious underlying diseases were selected to take part in the trial where sufficient hydration was performed before and after zoledronic acid administration and the patients were reminded to drink plenty of water after treatment. During the trial, no acute deterioration of renal function occurred in these patients. This has demonstrated that renal impairment is seldom caused by zoledronic acid and the sequential regimen does not increase the risk of zoledronic acid-associated renal impairment. Clinical screening should be conducted before treatment to identify whether zoledronic acid is suitable for a patient. During zoledronic acid treatment, regular monitoring of renal function is required, with particular attention to patients with preexisting impaired renal function. Undeniably, it requires further observation to verify whether the renal function documented a week after the treatment is a valid indicator for this study.

Alendronate sodium should be taken once weekly after an overnight fast and the patient should stand upright for at least 30 minutes after administration and ensure full awareness of any potential APR of the digestive tract; calcitonin-salmon nasal spray should be used daily while the patient should be aware of such adverse reactions as flushes and allergic response; raloxifene should be taken daily, with the potential side effects including flushes and flu-like symptoms. These adverse reactions are likely to reduce patient compliance with the abovementioned medications. Since zoledronic acid is a once-yearly infusion, patients are more likely to have good compliance with its administration and relevant precautions. However, the acute-phase response after zoledronic acid may reduce the compliance. In this study, different sequential regimens comprising zoledronic acid and other medications were used to persuade the patients into 
receiving a second dose of zoledronic acid, thereby increasing their compliance with the treatment. Through analysis, those who refused a second infusion were basically worried about the zoledronic acid-associated adverse reactions; some required further information of relevant diseases because they assumed that the course of treatment only included a single infusion; some decided not to receive a second dose of zoledronic acid for financial reasons. Despite the insignificant difference in APR between the raloxifene group and the control group, a greater number of the patients in the raloxifene group expressed their willingness to receive a second infusion. The main reason for such a shift of attitudes lies in the poor compliance with the daily administrated raloxifene.

\section{Limitations}

Several limitations of this study should be noted. All patients were under observation for one week only, with the common APRs as the monitoring indicators. The results of the trial are inevitably affected by the inherently subjective patients. Further analysis is required to investigate the long-term, zoledronic acid-associated adverse events or the effect on the long-term BMD. Besides, the statistical analysis might be underrepresented because a relatively small number of patients were included in each group.

\section{Conclusion}

Osteoporosis is a chronic disease that requires life-long treatment and good compliance. Patients showing poor compliance are more likely to experience fractures and relevant inconvenience caused by the disease [20]. If zoledronic acid is suitable for a patient who has reported low tolerance to the zoledronic acid-associated APR or anxiety after the first infusion, alendronate sodium or calcitonin can be administrated within a three-month course of treatment before zoledronic acid. The sequential treatment has been proved to effectively reduce such adverse reactions as fever, flu-like symptoms and bone pains triggered by zoledronic acid. Therefore, the sequential regimen with good patient compliance is considered a favorable solution to the long-term treatment of osteoporosis.

\section{References}

[1] Cosman, F., et al. (2011) Effects of Intravenous Zoledronic Acid plus Subcutaneous Teriparatide [rhPTH(1-34)] in Postmenopausal Osteoporosis. Journal of Bone and Mineral Research, 26, 503-511. https://doi.org/10.1002/jbmr.238

[2] Huang, S.S., Lin, H., Zhu, X.F., Chen, X., Fan, L. and Liu, C.C. (2014) Zoledronic Acid Increases Bone Mineral Density and Improves Health-Related Quality of Life over Two Years of Treatment in Chinese Women with Postmenopausal Osteoporosis. Endokrynologia Polska, 65, 96-104. https://doi.org/10.5603/EP.2014.0014

[3] Black, D.M., et al. (2015) The Effect of 6 versus 9 Years of Zoledronic Acid Treatment in Osteoporosis: A Randomized Second Extension to the HORIZON-Pivotal Fracture Trial (PFT). Journal of Bone and Mineral Research, 30, 934-944. https://doi.org/10.1002/jbmr.2442 
[4] Reid, I.R., Gamble, G.D., Mesenbrink, P., Lakatos, P. and Black, D.M. (2010) Characterization of and Risk Factors for the Acute-Phase Response after Zoledronic Acid. The Journal of Clinical Endocrinology \& Metabolism, 95, 4380-4387. https://doi.org/10.1210/jc.2010-0597

[5] Green, J.R., Muller, K. and Jaeggi, K.A. (1994) Preclinical Pharmacology of CGP 42'446, a New, Potent, Heterocyclic Bisphosphonate Compound. Journal of Bone and Mineral Research, 9, 745-751. https://doi.org/10.1002/jbmr.5650090521

[6] Rossini, M., Adami, S., Viapiana, O., et al. (2012) Circulating $\gamma \delta$ T Cells and the Risk of Acute-Phase Response after Zoledronic Acid Administration. Journal of Bone and Mineral Research, 27, 227-230. https://doi.org/10.1002/jbmr.521

[7] Roelofs, A.J., Jauhiainen, M., Mönkkönen, H., Rogers, M.J., Mönkkönen, J. and Thompson, K. (2009) Peripheral Blood Monocytes Are Responsible for $\gamma \delta$ T Cell Activation Induced by Zoledronic Acid through Accumulation of IPP/DMAPP. British Journal of Haematology, 144, 245-250. https://doi.org/10.1111/j.1365-2141.2008.07435.x

[8] Schweitzer, D.H., Oostendorp-van de Ruit, M., van der Pluijm, G., Löwik, C.W.G.M. and Papapoulos, S.E. (1995) Interleukin-6 and the Acute Phase Response during Treatment of Patients with Paget's Disease with the Nitrogen-Containing Bisphosphonate Dimethylaminohydroxypropylidene Bisphosphonate. Journal of Bone and Mineral Research, 10, 956-962. https://doi.org/10.1002/jbmr.5650100617

[9] Adami, S., et al. (1987) The Acute-Phase Response after Bisphosphonate Administration. Calcified Tissue International, 41, 326-331. https://doi.org/10.1007/BF02556671

[10] Mehta, N.M., Malootian, A. and Gilligan, J.P. (2003) Calcitonin for Osteoporosis and Bone Pain. Current Pharmaceutical Design, 9, 2659-2676. https://doi.org/10.2174/1381612033453622

[11] Yang, N.N., Venugopalan, M., Hardikar, S. and Glasebrook, A. (1996) Identification of an Estrogen Response Element Activated by Metabolites of $17 \beta$-Estradiol and Raloxifene. Science, 273, 1222-1225. https://doi.org/10.1126/science.273.5279.1222

[12] Huang, T., et al. (2013) Treatment of Osteoporosis in Postmenopausal Women with Raloxifene: A Systematic Review. Chinese Journal of Osteoporosis, 19, 391-397.

[13] Shao, Y., Pan, Z.G., Wei, Q.S., Liu, F., Sun, W.S. and Deng, W.M. (2016) Advance in the Study of Osteoporosis in Guangdong Province in Recent 5 Years. Chinese Journal of Osteoporosis, 2, 238-244.

[14] John, C.A. (2010) Review of the Cardiovascular Safety of Zoledronic Acid and Other Bisphosphonates for the Treatment of Osteoporosis. Clinical Therapeutics, 32, 426-436. https://doi.org/10.1016/j.clinthera.2010.03.014

[15] Reid, I.R., Bristow, S.M. and Bolland, M.J. (2015) Calcium Supplements: Benefits and Risks. Journal of Internal Medicine, 278, 354-368. https://doi.org/10.1111/joim.12394

[16] Black, D.M., et al. (2007) Once-Yearly Zoledronic Acid for Treatment of Postmenopausal Osteoporosis. The New England Journal of Medicine, 356, 1809-1822. https://doi.org/10.1056/NEJMoa067312

[17] Kim, D.H., Rogers, J.R., Fulchino, L.A., Kim, C.A., Solomon, D.H. and Kim, S.C. (2015) Bisphosphonates and Risk of Cardiovascular Events: A Meta-Analysis. PLoS $O N E, 10$, e0122646. https://doi.org/10.1371/journal.pone.0122646

[18] Kim, S.Y., Kim, M.J., Cadarette, S.M. and Solomon, D.H. (2010) Bisphosphonates and Risk of Atrial Fibrillation: A Meta-Analysis. Arthritis Research \& Therapy, 12, R30. https://doi.org/10.1186/ar2938 
[19] Munier, A., et al. (2005) Zoledronic Acid and Renal Toxicity: Data from French Adverse Effect Reporting Database. Annals of Pharmacotherapy, 39, 1194-1197. https://doi.org/10.1345/aph.1E589

[20] Akehurst, R., Brereton, N., Ariely, R., et al. (2011) The Cost Effectiveness of Zoledronic Acid $5 \mathrm{mg}$ for the Management of Postmenopausal Osteoporosis in Women with Prior Fractures: Evidence from Finland, Norway and the Netherlands. Journal of Medical Economics, 14, 53-64. https://doi.org/10.3111/13696998.2010.545563

\section{Patient Information}

\begin{tabular}{|c|c|}
\hline Group & Date of Enrollment \\
\hline Name & Medical Record No. \\
\hline Sex & Age \\
\hline Weight & Tel \\
\hline \multicolumn{2}{|l|}{ Underlying Disease(s) } \\
\hline \multicolumn{2}{|l|}{ Medication History } \\
\hline Lumbar spine BMD & Hip BMD \\
\hline VAS upon Enrollment & $\beta$-cross upon Enrollment \\
\hline Ca upon Enrollment & $\begin{array}{l}\text { Creatinine upon } \\
\text { Enrollment }\end{array}$ \\
\hline \multicolumn{2}{|l|}{$\begin{array}{l}\text { Pre-treatment Adverse } \\
\text { Reactions }\end{array}$} \\
\hline Pre-treatment VAS & Pre-treatment $\beta$-cross \\
\hline Pre-treatment $\mathrm{Ca}$ & Pre-treatment Creatinine \\
\hline $\begin{array}{l}\text { Pre-treatment Body } \\
\text { Temperature }\end{array}$ & $\begin{array}{l}\text { Post-treatment Body } \\
\text { Temperature } \\
\text { (peak temperature) }\end{array}$ \\
\hline Onset & Duration \\
\hline \multicolumn{2}{|l|}{$\begin{array}{l}\text { Post-treatment VAS } \\
\text { (a week after injection) }\end{array}$} \\
\hline $\begin{array}{c}\text { Post-treatment Ca } \\
\text { (a week after injection) }\end{array}$ & $\begin{array}{l}\text { Post-treatment Creatinine } \\
\text { (a week after injection) }\end{array}$ \\
\hline $\begin{array}{l}\text { Pharmaceutical } \\
\text { Intervention }\end{array}$ & $\square$ Yes $\square$ No \\
\hline $\begin{array}{l}\text { Adverse Reactions (e.g., } \\
\text { palpitation, oliguria, tics) }\end{array}$ & $\square$ Yes $\square$ No \\
\hline
\end{tabular}




\section{Questionnaire on Zoledronic Acid Treatment (Group}

Instructions: Please complete the following questions to reflect your opinions as accurately as possible and to answer factual questions to the best of your knowledge a week after the administration of Zoledronic Acid.

1) Did you strictly follow the doctor's advice?
A. Yes
B. No

2) Did you adhere to the three-month medication before intravenous injection of Zoledronic Acid?
A. Yes
B. No
C. Not really (missing one or several doses)

3) Why did you fail to adhere to the medication/miss one or several doses?

A. I forgot to take the medicine.

B. I was afraid of relevant side effects.

C. I didn't feel like taking the medicine.

4) Did you notice any adverse reactions during the three-month medication before intravenous injection of Zoledronic Acid?
A. Yes (go to Question 5)
B. No (go to Question 6)

5) What specifically are the main adverse reactions triggered by the medication before intravenous injection of Zoledronic Acid?
A. Fever ( $\square$ Mild; $\square$ Moderate; $\square$ Severe)
B. Bone pains (VAS: $\square$ 1; $\square$ 2; $\square 3$; $\square$ 4)
C. Abdominal pain, nausea D. Rhinitis, rhinorrhea
E. Rash
F. Other (please specify)

6) Did you notice any adverse reactions following the intravenous injection of Zoledronic Acid?
A. Yes (go to Question 7)
B. No (go to Question 8)

7) What specifically are the main adverse reactions caused by the injection?

A. Fever ( $\square$ Mild; $\square$ Moderate; $\square$ Severe)

B. Bone pains (VAS: $\square$;; $\square 2$; $\square 3$; $\square$ 4)

C. Flu-like symptoms (including fever, chills, exhaustion, body aches and catarrh, rhinorrhea, sneezing abdominal pain, nausea)
D. Palpitation
E. Oliguria
F. Rash
H. Other (please specify)

8) Based on your experience of the intravenous injection and the oral administration, which do you prefer?
A. Non-intravenous injection (e.g., oral administration, nasal spray)
B. Intravenous injection

9 Are you willing to take a second dose of Zoledronic Acid in the following 
year? (Note: Patients with osteoporosis are generally recommended to receive three consecutive doses of Zoledronic Acid.)
A. Yes
B. No
C. Not sure

Please specify the reason for your answer to Question 8: 